\title{
PENGARUH PEMERIKSAAN DAN PELAKSANAAN SELF ASSESMENT SYSTEM TERHADAP TINGKAT KEPATUHAN WAJIB PAJAK BADAN PADA KANTOR PELAYANAN PAJAK (KPP) PRATAMA BANDA ACEH
}

\author{
Cut Delsie Hasrina ${ }^{1}$ Yusri $^{2}$, Nona Maulina ${ }^{3}$ \\ 1) 2) 3) Program Studi Akuntansi Fakultas Ekonomi, Universitas Abulyatama \\ Jl. Blang Bintang Lama Km 8,5 Lampoh Keude Aceh Besar \\ email: cut.hasrina@yahoo.com
}

\begin{abstract}
The purpose of this research is to determine the effect of examination and implementation of self assessment system on the level of compliance with corporate tax payers registered in Taxes Service Office (KPP) Pratama Banda Aceh. The used data is in form of primary data by giving the questionnaire to the taxpayers. The sampling technique is random sampling. The sample of this study is 100 respondents, from 100 respondents, there are not all questionnaires did not return because there were 9 questionnaires were not returned, 7 questionnaires were incomplete and therefore unusable. The results showed that, inspection and implementation of self assessment system significantly influence taxpayer compliance rate on KPP Banda Aceh by testing simultaneously with the value of $F_{\text {score }}>F_{\text {table }}$ and the value of $T_{\text {score }}>T_{\text {table }}$.
\end{abstract}

Keywords : Examination and Self Assessment System Implementation, Compliance Level Against the taxpayer.

\begin{abstract}
Abstrak: Penelitian ini bertujuan untuk mengetahui pengaruh pemeriksaan dan pelaksanaan self assessment system terhadap tingkat kepatuhan wajib pajak badan yang terdaftar pada Kantor Pelayanan Pakak (KPP) Pratama Banda Aceh. Data yang digunakan berupa data primer dengan membagi kuesioner kepada wajib pajak badan, Teknik penentuan sampel menggunakan simple random sampling. Jumlah sampel yang diambil dalam penelitian ini berjumlah 100 orang responden, dari 100 orang responden tidak semua data (kuesioner) bisa kembali karena ada 9 kuesioner yang tidak kembali, 7 kuesioner yang tidak lengkap sehingga tidak dapat digunakan. Hasil penelitian menunjukkan bahwa, pemeriksaan dan pelaksanaan self assesment system berpengaruh signifikan terhadap tingkat kepatuhan wajib pajak badan pada KPP Pratama Banda Aceh berdasarkan uji simultan dengan nilai $\mathrm{F}_{\text {hitung }}>\mathrm{Ft}_{\text {abel }}$ dan nilai $\mathrm{T}_{\text {hitung }}>\mathrm{T}$ tabel.
\end{abstract}

Kata Kunci : Pemeriksaan dan pelaksanaan self assesment system, tingkat kepatuhan wajib pajak badan.

Di negara berkembang seperti Indonesia, pajak merupakan salah satu pendapatan terbesar negara karena dengan pajak negara bisa membiayai pengeluaran-pengeluaran umum berhubungan dengan tugas negara untuk menyelenggarakan pemerintahan. Dalam menjalankan pemerintahan dan pembangunan pemerintah membutuhkan dana yang tidak sedikit. Dana tersebut dikumpulkan dari iuran masyarakat atau yang sering disebut pajak maupun dari segenap potensi sumber daya hasil kekayaan alam.

Menurut Supramono \& Damayanti (2005:10) Sistem pemungutan pajak di Indonesia telah beberapa kali mengalami perubahan, dari tahun 
1967 Indonesia menggunakan Official Assesment System dan telah diganti dengan semi Self Assesment System (1968-1983). Baru pada tahun 1984 atas perubahan Undang-undang tahun 1983 , sistem pemungutan pajak di Indonesia menggunakan Self Assesment System. Self Assesment System merupakan dimana Wajib Pajak boleh menghitung, membayar dan melaporkan sendiri besar pajak yang harus di setor. Dalam sistem ini wajib pajak bersifat aktif sedangkan Fiskus hanya mengawasi.

Menurut Purwono (2010) Sistem Self Assesment System mulai diaplikasikan bersamaan dengan informasi perpajakan tahun 1983 setelah terbitnya UU No.6 Tahun 1983 tentang ketentuan umum dan tata cara perpajakan yang mulai berlaku sejak tanggal 1 januari 1984. Sistem Self Assesment diterapkan atas dasar kepercayaan pihak Fiskus kepada Wajib Pajak namun dalam pelaksanaannya, sistem pemungutan pajak berdasarkan Self Assesment System yang memberikan kepercayaan dan tanggung jawab penuh kepada Wajib Pajak untuk menghitung dan memperhitungkan dan melaporkan sendiri jumlah pajak yang terutang, dalam kehidupan yang sesungguhnya sulit berjalan sesuai dengan yang diharapkan atau bahkan disalah gunakan dalam memenuhi tugas perpajakan.

Ketidak patuhan wajib pajak dalam Self Assesment System dapat berkembang apabila tidak adanya ketegasan dan tindak lanjut dari aparat pajak. Hal ini dapat mencapai suatu tingkat dimana sistem perpajakan menjadi lumpuh kebijakan penerapan Self Assesment System. Untuk itu siwajib pajak diwajibkan untuk lebih mendalami peraturan perundang-undangan perpajakan yang berlaku agar Wajib Pajak dapat melaksanakan kewajiban perpajakan dengan baik.

Permasalahan yang dihadapi adalah ada argument bahwa Wajib Pajak Badan yang terdaftar di Kantor Pelayanan Pajak Pratama Banda Aceh dengan di berlakukannya Self Assesment System para Wajib Pajak Badan tidak melakukan kewajiban perpajakannya dengan baik dan benar sesuai dengan ketentuan yang berlaku. Untuk menyangkal terhadap pernyataan yang kurang diinginkan tersebut sehingga peneliti perlu mengadakan penelitian tentang pengaruh pemeriksaan dan pelaksanaan self assesment system terhadap tingkat kepatuhan wajib pajak badan pada Kantor Pelayanan Pajak (KPP) Pratama Banda Aceh.

Berdasarkan latar belakang diatas, maka permasalahan dari penelitian ini adalah apakah pemeriksaan dan pelaksanaan self assesment System berpengaruh tingkat kepatuhan wajib pajak badan yang dilaksanakan oleh Kantor Pelayanan Pajak (KPP) Pratama Banda Aceh.

Berdasarkan identifikasi masalah yang sudah diuraikan diatas maka tujuan dari penelitian ini adalah Untuk mengetahui pengaruh pemeriksaan dan pelaksanaan Self Assesement System terhadap kepatuhan wajib pajak badan yang dilaksanakan pada Kantor Pelayanan Pajak (KPP) Pratama Banda Aceh

\section{METODE PENELITIAN}

\section{Populasi dan Sampel}

Populasi dalam penelitian ini adalah seluruh Wajib Pajak Badan yang kurang bayar termasuk WP badan yang pendapatannya nihil akibat penerapan Pajak Badan di KPP Pratama Banda 
Aceh, khususnya Kota Banda Aceh. Menurut Riduwan (2014:12), teknik penentuan sampel menggunakan simple random sampling yaitu pengambilan sampel dari anggota populasi dengan menggunakan acak tanpa memperhatikan strata (tingkatan) dalam anggota populasi tersebut. Sampel yang akan diambil untuk pengambilan data adalah sebanyak 100 responden.

\section{Teknik Pengumpulan Data}

Teknik pengumpulan data yang digunakan dalam penelitian ini adalah

Penelitian Kepustakaan merupakan salah satu cara untuk memperoleh data dengan membaca literatur-literatur dan buku yang berkaitan dengan permasalahan yang diteliti,

Penelitian Lapangan, dilakukan dengan cara mengedarkan daftar pertanyaan (kuesioner) kepada responden, yaitu pada Wajib pajak yang terdaftar Pada Kantor Pelayanan Pajak Pratama Banda Aceh.

\section{Operasional variabel}

Variabel penelitian yang digunakan dalam penelitian ini terdiri dari variabel independen, yaitu Pemeriksaan $\left(\mathrm{X}_{1}\right)$ dan Pelaksanaan Self Asesment System $\left(\mathrm{X}_{2}\right)$ dan satu variabel dependen yaitu Kepatuhan Wajib Pajak Badan (Y). Metode Analisa Data

Adapun metode analisis data digunakan untuk menjawab hipotesis penelitian yaitu, untuk mengetahui pengaruh tidaknya pengaruh pemeriksaan dan pelaksanaan self assessment system terhadap tingkat kepatuhan wajib pajak badan adalah dengan analisis regresi linier berganda dengan bantuan program SPSS Versi 20 . Dengan persamaan sebagai berikut : Damodar
(2006:125)

$$
\mathbf{Y}=\alpha+\beta_{1} X_{1}+\beta_{2} X_{2}+\varepsilon
$$

Keterangan :

$\mathrm{Y} \quad=$ Kepatuhan Wajib Pajak Badan

$\alpha \quad=$ Konstanta

$\mathrm{X}_{1} \quad=$ Pemeriksaan

$\mathrm{X}_{2} \quad=$ Pelaksanaan Self Assesment System

$\beta_{1} \beta_{2}=$ Koefisien $X_{1} X_{2}$

$\varepsilon \quad=$ Error term

\section{HASIL DAN PEMBAHASAN}

Analisis Pengaruh Pemeriksaan dan Pelaksanaan Self Assesment System Terhadap Tingkat Kepatuhan Wajib Pajak Badan Pada Kantor Pelayanan Pajak (KPP) Pratama Banda Aceh

Hasil pengujian regresi pada penelitian ini dilakukan untuk mengetahui apakah variabel Pemeriksaan dan Pelaksanaan Self Assesment System Terhadap Tingkat Kepatuhan Wajib Pajak Badan. Adapun hasil pengolahan data dengan menggunakan regresi linear berganda dari penelitian ini dapat dilihat dari hasil regresi berganda pada tabel 1 .

Tabel 1. Hasil regeresi linear berganda

\begin{tabular}{|c|c|c|c|c|c|c|c|}
\hline \multicolumn{8}{|c|}{ Coefficients $^{\mathrm{a}}$} \\
\hline \multirow[t]{2}{*}{ Model } & \multicolumn{2}{|c|}{$\begin{array}{l}\text { Unstandardized } \\
\text { Coefficients }\end{array}$} & \multirow{2}{*}{$\begin{array}{c}\begin{array}{c}\text { Standardized } \\
\text { Coefficients }\end{array} \\
\text { Beta }\end{array}$} & \multirow[t]{2}{*}{$\mathrm{t}$} & \multirow[t]{2}{*}{ Sig. } & \multicolumn{2}{|c|}{ Collinearity Statistics } \\
\hline & B & $\begin{array}{l}\text { Std. } \\
\text { Error }\end{array}$ & & & & Tolerance & VIF \\
\hline (Constant) & 16.796 & 3.157 & & 5.320 & .000 & & \\
\hline $1 \quad \mathrm{x} 1$ & .241 & .136 & .220 & 1.774 & .080 & .489 & 2.044 \\
\hline $\mathrm{x} 2$ & .510 & .140 & .450 & 3.629 & .000 & .489 & 2.044 \\
\hline
\end{tabular}

Berdasarkan hasil pengolahan data seperti terlihat pada Tabel 1 Kolom Unstandardized Coefficients bagian B diperoleh persamaan regresi linier berganda sebagai berikut: 
$\mathrm{Y}=16.796+0,241 \mathrm{X}_{1}+0,510 \mathrm{X}_{2}+\mathrm{e}$

Berdasarkan persamaan tersebut dapat digambarkan sebagai berikut :

a. Konstanta (a) $=16.796$, ini mempunyai arti bahwa variabel tingkat kepatuhan wajib pajak badan (Y) memiliki hubungan positif sebesar 16.796. Diinterprestasikan apabila variabel pemeriksaan $\left(\mathrm{X}_{1}\right)$, dan pelaksanaan self assessment system $\left(\mathrm{X}_{2}\right)$ sama dengan 0 maka kepatuhan wajib pajak badan akan tetap sebesar 16.796 .

b. Nilai Koefisien $\mathbf{X}_{\mathbf{1}}\left(\mathbf{b}_{1}\right)=0,241$, pengaruh variabel tingkat kepatuhan wajib pajak badan (Y) memiliki hubungan positif sebesar 0,241. Diinterprestasikan jika pemeriksaan sebesar 1\% maka akan terjadi kenaikan sebesar 0,241terhadap tingkat kepatuhan wajib pajak badan.

c. Nilai Koefisien $\mathbf{X}_{2}\left(\mathbf{b}_{2}\right)=0,510$, pengaruh variabel tingkat kepatuhan wajib pajak badan (Y) memiliki hubungan positif sebesar 0,510. Diinterprestasikan jika pelaksanaan self assessment system positif sebesar 1\% maka akan terjadi kenaikan sebesar 0,510 terhadap tingkat kepatuhan wajib pajak badan.

\section{Pengujian Hipotesis}

\section{Uji Secara Simultan (Uji-F)}

Uji secara simultan atau uji secara serentak dilakukan untuk melihat secara bersama-sama pengaruh positif dan signifikan variabel bebas $\left(\mathrm{X}_{1}\right.$, $\mathrm{X}_{2}$ ) yang terdiri dari variabel pemeriksaan dan pelaksanaan self assessment system terhadap tingkat kepatuhan wajib pajak badan pada Kantor Pelayanan Pajak (KPP) Pratama Banda Aceh (Y).
Tabel 2. Uji Secara Simultan

\begin{tabular}{|c|c|c|c|c|c|c|}
\hline \multicolumn{7}{|c|}{ ANOVA $^{a}$} \\
\hline \multicolumn{2}{|c|}{ Model } & Sum of & Df & Mean & $\mathrm{F}$ & Sig. \\
\hline \multirow{3}{*}{1} & Regression & 400.879 & 2 & 200.440 & 26.074 & $.000^{\mathrm{b}}$ \\
\hline & Residual & 622.680 & 81 & 7.687 & & \\
\hline & Total & 1023.560 & 83 & & & \\
\hline
\end{tabular}

Sumber Hasil Penelitian 2015 diolah.

Dari tabel 2, didapat nilai $F_{\text {hitung }}$ sebesar 26.074, sedangkan $F_{\text {tabel }}$ yaitu $F((3,11) ; 0,05) 3,11$. Sehingga $\quad F_{\text {hitung }}>F_{\text {tabel }}(26.074>3,11)$ dan signifikan pada tingkat 0.000 . Hasil tersebut membuktikan bahwa sehingga variabel bebas yang terdiri dari variabel pemeriksaan $\left(\mathrm{X}_{1}\right)$ dan pelaksanaan self assessment system $\left(\mathrm{X}_{2}\right)$ secara bersama-sama berpengaruh signifikan terhadap tingkat kepatuhan wajib pajak badan pada Kantor Pelayanan Pajak (KPP) Pratama Banda Aceh (Y).

\section{Uji Secara Parsial (Uji-t)}

Uji t dilakukan untuk menguji secara parsial variabel bebas yang terdiri dari variabel pemeriksaan $\left(\mathrm{X}_{1}\right)$ dan pelaksanaan self assessment system $\left(\mathrm{X}_{2}\right)$ dan yang menjadi variabel dependen adalah tingkat kepatuhan wajib pajak badan pada Kantor Pelayanan Pajak Pratama Banda Aceh (Y)

Tabel 3. Hasil Uji t

\begin{tabular}{|c|c|c|}
\hline Model & $\mathrm{T}$ & Sig. \\
\hline (Constant) & 5.320 & .000 \\
\hline $1 \quad x 1$ & 1.774 & .080 \\
\hline$x 2$ & 3.629 & .000 \\
\hline
\end{tabular}

Sumber : Hasil 2015 diolah.

Berdasarkan tabel diatas terlihat bahwa:

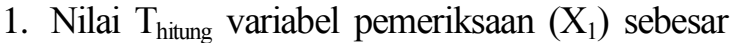
1.774 dilihat dari tabel 3) sementara nilai $T_{\text {tabel }}$ 
adalah sebesar 1.713. nilai $\mathrm{T}_{\text {hitung }}$ yang diperoleh dalam penelitian lebih besar dibandingkan dengan nilai $\mathrm{T}_{\text {tabel, }}$ sehingga hal ini menunjukkan bahwa variabel pemeriksaan berpengaruh terhadap tingkat kepatuhan wajib pajak badan pada KPP Pratama Banda Aceh.

2. Untuk $T_{\text {hitung }}$ variabel pelaksanaan self assessment system $\left(\mathrm{X}_{2}\right)$ sebesar 3.629 dilihat dari tabel 3) sementara nilai $T_{\text {tabel }}$ adalah sebesar 1.713. nilai $\mathrm{T}_{\text {hitung }}$ yang diperoleh dalam penelitian ini lebih besar dibandingkan nilai $\mathrm{T}_{\text {tabel, }}$, sehingga hal ini menunjukkan bahwa variabel pelaksanaan self assessment system berpengaruh terhadap tingkat kepatuhan wajib pajak badan pada KPP Pratama Banda Aceh.

Berdasarkan pengujian secara parsial dapat disimpulkan bahwa semakin tinggi pelaksanaan self assessment system semakin tinggi juga tingkat kepatuhan wajib pajak badan untuk melaporkan pajaknya secara tepat waktu, jujur dan lengkap pada KPP Pratama Banda Aceh.

Variabel pemeriksaan berpengaruh signifikan terhadap terhadap tingkat kepatuhan wajib pajak badan pada KPP Pratama Banda Aceh. Hal ini terbukti $T_{\text {hitung }}>T_{\text {tabel }}$ (variabel pemeriksaan $\left(X_{1}\right)$ sebesar 1.774 dilihat dari tabel 3.3) sementara nilai $\mathrm{T}_{\text {tabel }}$ adalah sebesar $1.713>1.713$ ).

Variabel pelaksanaan self assessment system berpengaruh signifikan terhadap tingkat kepatuhan wajib pajak badan pada KPP Pratama Banda Aceh. Hal ini terbukti $\mathrm{T}_{\text {hitung }}>\mathrm{T}_{\text {tabel }}(3.751>1.713)$. Berdasarkan hasil penelitian ini jika dikaitkan dengan kenyataan bahwa semakin tinggi kepercayaan aparat pajak terhadap wajib pajak dalam menghitung, memperhitungkan, dan melaporkan sendiri jumlah pajak yang terutang maka akan semakin patuh wajib pajak dalam melaksanakan perpajakan.

\section{KESIMPULAN DAN SARAN}

\section{Kesimpulan dari pemeriksaan ini adalah:}

1. Pemeriksaan berpengaruh kepatuhan wajib pajak badan pada KPP Pratama Banda Aceh berdasarkan uji simultan dengan nilai $\mathrm{F}_{\text {hitung }}$ yang diperoleh sebesar $25.406 \mathrm{H}_{0}$ dalam penelitian ini ditolak dan mengandung makna bahwa hipotesis hal dalam penelitian ini diterima.

2. Pelaksanaan Self Assesment System berpengaruh signifikan Terhadap Tingkat Kepatuhan Wajib Pajak Badan pada KPP Pratama Banda Aceh berdasarkan uji simultan dengan nilai $\mathrm{T}_{\text {hitung }}$ yang diperoleh sebesar 1.774 penelitian $\mathrm{H}_{0}$ dalam penelitian ini ditolak, maka dapat disimpulkan bahwa hipotesis $\mathrm{H}_{2}$ dalam penelitian ini diterima.

3. Variabel Pemeriksaan dan pelaksanaan self assessment system berpengaruh terhadap Tingkat Kepatuhan Wajib Pajak Badan pada KPP Pratama Banda Aceh berdasarkan uji parsial dengan nilai $\mathrm{T}_{\text {hitung }} 3.629$ dan mengandung makna bahwa hipotesis $\mathrm{H}_{3}$ dalam penelitian ini diterima.

4. Pada penelitian ini dapat disimpulkan bahwa seluruh hipotesis (Ha1, Ha2, dan Ha3) yang diuji tidak ada yang ditolak akan tetapi dapat diterima.

\section{Saran}

Saran yang diberikan dari penelitian ini adalah: peneliti selanjutnya dapat menggunakan 
faktor-faktor lain yang dapat dianalisa berkenanaan dengan judul.

\section{DAFTAR PUSTAKA}

Gujarati Damodar. (2006). Dasar-Dasar Ekonomentrika. Edisi ketiga jilid 1. Jakarta: Penerbit Erlangga.

Supramono dan Damayanti, T.W., (2005). Perpajakan Indonesia : Mekanisme dan Perhitungannya. Yogyakarta: Penerbit Andi.

Purwono Hery. (2010). Dasar-dasar Perpajakan dan Akuntansi Pajak. penerbit Erlangga dicetak oleh Gelora Aksara Pratama.

Riduwan, M.B.A. (2014). Dasar-dasar Statistika. cetakan ke 12. Bandung: Alphabet Bandung. 